\title{
Canadian approval sought for controversial pain drug
}

A

s Americans campaign to revoke approval of Zohydro, a new opioid pain medication, the Canadian licence-holder says it is planning to submit the drug to Health Canada for approval. Zohydro (hydrocodone bitartrate) is a highdose, extended-release opioid for the treatment of chronic pain that requires around-the-clock management and has failed to respond to other medications.

"We did our due diligence with potential prescribers and they said this is something that would be useful for patients in their practice," said Mark Beaudet, interim president and CEO of Paladin Labs, which holds the Canadian licence for the drug. "There would indeed be a need for it."

"This is a drug that nobody needs," counters Dr. David Juurlink, head of the Division of Clinical Pharmacology and Toxicology at Sunnybrook Health Sciences Centre in Toronto, Ontario, and coauthor of an article critical of the US Food and Drug Administration's (FDA) approach to approving opioids, including Zohydro (Expert Opin Drug Saf 2014;13:407-10). “There's really no bigger drug safety crisis facing North Americans today."

In the United States, where Zohydro was approved by the FDA in the fall of 2013, Fed Up!, a coalition of 40 medical and addiction professionals as well as grassroots groups, wrote an open letter to the FDA calling for Zohydro's approval to be revoked because of concern about misuse and addiction.

Opioids are often misused - cut, crushed or broken down with solvents - and then snorted or injected for a high, either by people to whom they are prescribed or those who obtain them illegally.

"People would get these prescriptions and sell them on the street. I would worry that people would sell the drug to pay for groceries and it ends up up the nose of some young addict," says Juurlink.

Although the main prescription opioid drug abused 5 to 10 years ago was Oxycontin (oxycodone), its use waned because of a new formulation called OxyNeo, that was tamper- and abuse-

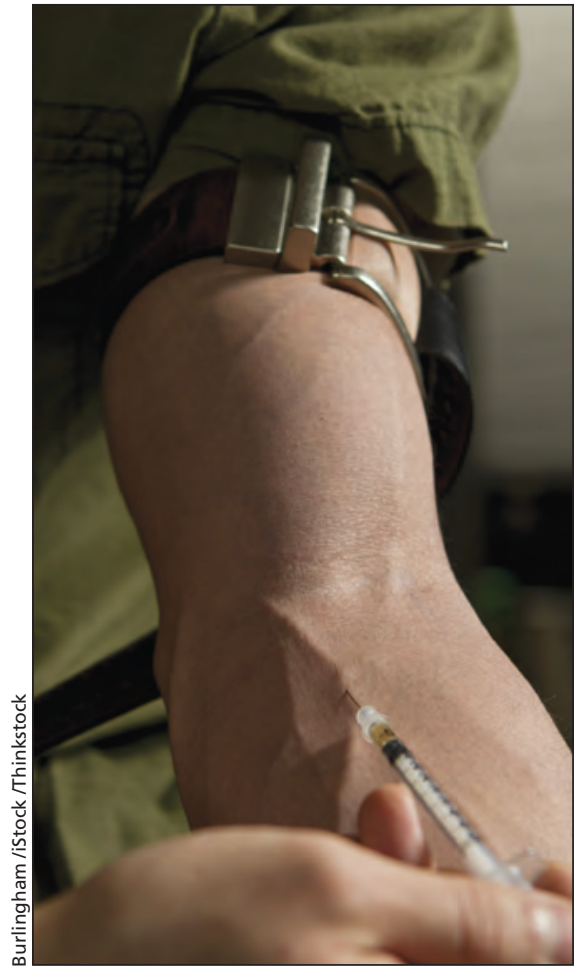

Those who oppose the sale of Zohydro fear it will end up as another anti-pain prescription that is abused on the streets.

resistant. Its hard coating resisted cutting or crushing and formed a gel when exposed to water to prevent uncontrolled release from the powdered form.

In the US, Zohydro may soon be available in a tamper-resistant formulation now being developed by Altus Formulation Inc. in Mirabel, Quebec. Altus' "Intellitab" formulation differs from that used for OxyNeo, explains CEO Damon Smith. "It comprises a number of aspects working together."

Altus' tablets are very hard in order to discourage cutting, but even when they are cut or crushed the controlledrelease aspect of the drug is maintained. "It doesn't give you that rapid 'dose dump' that you need for euphoria," says Smith. If dissolved in water, alcohol or other solvents, the tablets form a gel that is difficult to get into a syringe and stops the syringe from functioning. The tablets are safe for legitimate patients, Smith emphasizes. "We didn't want to put in noxious substances that would affect patients."

Altus has licensed the technology to Zohydro's US manufacturer, Zogenix
Inc., and is currently developing the tamper-resistant form.

Although Beaudet at Paladin Labs would not confirm that the Canadian product would use the Intellitab formulation, Paladin is a minority shareholder in Altus.

But tampering is only part of the abuse picture. "You don't have to crush up something to abuse it - some people are swallowing it," says Dr. Lisa Lefebvre, medical head of the Addiction Medicine Service at the Centre for Addiction and Mental Health in Toronto, Ont.

"The key is that tamper-resistant formulations are good, but they are not the only thing that is going to help solve the problem," says Lefebvre, adding that some patients with pain who are prescribed opioids become addicted. "We need to focus on safe prescribing and recognition of addiction." She points to the 2010 Canadian Guideline for Safety and Effective Use of Opioids in Chronic Non-Cancer Pain, saying that, although progress has been made, "we need to support prescribers to make changes in their practice to prescribe more safely."

Juurlink agrees. "We still prescribe opioids too much, at doses that are not just inadvisable but also dangerous. Nobody quibbles with the use of opioids in acute pain or palliative care. But we have enough opioids - there are plenty of options for palliative care and for chronic care."

But Beaudet maintains that Zohydro fills a therapy gap: "There is no singleagent extended-release hydrocodone available in Canada today. Not all patients respond to all pain products." On its website, Zogenix states that, unlike Zohydro, most opioid drugs are combined with acetaminophen, which poses a risk of hepatic toxicity with long-term use.

"Any decision to approve any new opioid has to balance concerns with the needs of those who are in pain and for whom existing treatments are not sufficient," says Beaudet. — Carolyn Brown, Ottawa, Ont.

CMAJ 2014. DOI:10.1503/cmaj.109-4765 